\title{
Chemical composition and pulping of banana pseudo-stems
}

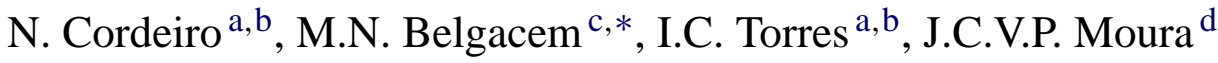 \\ ${ }^{a}$ Departamento de Química, Universidade da Madeira, 9000-390 Funchal, Portugal \\ ${ }^{\mathrm{b}}$ Centro de Estudos da Macaronésia, Universidade da Madeira, 9000-390 Funchal, Portugal \\ ${ }^{\mathrm{c}}$ Ecole Française de Papeterie et des Industries Graphiques (EFPG) de Grenoble, \\ Domaine Universitaire, BP65, 38402 Saint Martin D'Hères, France \\ d Departamento de Química, Universidade do Minho, 4700-320 Braga, Portugal
}

Received 17 January 2003; accepted 10 September 2003

\begin{abstract}
This paper deals with the determination of chemical composition and the study of the pulping potentialities of banana pseudo-stems growing in Madeira Island (Portugal). First, the raw material was both studied as a whole (type I) and as the outer bark part (type II), which is richer in cellulose fibres. Before starting the cooking of banana wastes, the main components of the two types of material were quantified, and showed that the polysaccharide content was high enough (about 60-70\%) to justify the pulping investigations. Moreover, the lignin content was very low (approximately 12\%). The only discouraging finding was the relative high amounts of ashes and extractives. The pulping of these residues was carried out using soda, kraft and soda-anthraquinone (AQ) cooking processes and the optimal pulping conditions were established. Thus, pulps with a yield of about 37-38\% with a Kappa number (Kappa no.) about 30-32 were obtained when cooking in the presence of $0.25-0.35 \%$ of anthraquinone at $120^{\circ} \mathrm{C}$ for a short cooking time, i.e. $30 \mathrm{~min}$. The longer times and higher temperatures of cooking as well as the use of kraft pulping conditions did not give rise to better performances, comparing to those mentioned above. These severe conditions were detrimental to the hemicellulose preservation.
\end{abstract}

(C) 2003 Elsevier B.V. All rights reserved.

Keywords: Musa acuminata Colla; Agricultural residues; Non-wood pulp; Annual plant; Soda-anthraquinone pulps; Fibres properties

\section{Introduction}

Over the years, an increasing preoccupation regarding forest preservation and rational use of forest and agricultural residues has occurred. This fact was mainly motivated by the increasing consumption of wood fibre-based products, such as panel, paper

\footnotetext{
* Corresponding author. Tel.: +33-4-7682-6962; fax: +33-4-7682-6933.

E-mail addresses: belgacem@efpg.inpg.fr, prenom.nom@efpg.inpg.fr (M.N. Belgacem).
}

and boards. This demand is currently solved by using increasing amounts of recycled fibres. Thus, in some paper grades, more than $50 \%$ of raw materials are secondary fibres. Annual plants could also be a new source of lignocellulosic fibres for papermaking and/or composite materials.

In Madeira Island (Portugal) the production of banana, Musa acuminata Colla, has a capital economical importance. This agricultural activity generates a large amount of residues, because each plant produces only one bunch of bananas, after its harvesting the bare pseudo-stems are cut and usually left in the 
soil plantation to be used as organic material. Thus, it could be estimated that few tons per hectare are produced annually. As we believe, these crops could and should find a more rational way of utilisation, namely as a source of cellulosic fibres. In this context, we have recently started a research program aiming to deep the knowledge on chemical and structural constitution of banana plants (Oliveira et al., 2002) and the use of its cellulosic fibres in papermaking composition and as reinforcing fibres in composite materials (Faria et al., 2002).

These approaches offer several advantages, since these raw materials can be produced annually and have generally lower lignin contents. They are more easily delignified and require milder and faster cooking conditions comparing with wood fibre sources. The resulting pulp can be used mainly in paper and board, fibre-board and composite materials.

This paper deals with the results of chemical composition of banana crops as well as their soda, soda-anthraquinone (AQ) and kraft pulping optimisation. To the best of our knowledge, the few works dealing with the use of banana crops as a source of fibres concerns varieties which are different from our raw material, namely: Musa paradisiaca L., Musa sapientum and Musa cavendishii (Darkwa, 1998; Soffner et al., 2000; Soffner and Silva, 2000). These studies showed that $9 \%$ of active alkali cooking of $M$. paradisiaca $\mathrm{L}$. crops produced pulps of $59 \%$ yield and Kappa number (Kappa no.) of 30. The fibres obtained by kraft cooking of the first two species have an average length of about $3.9 \mathrm{~mm}$ which explain their high strength properties (Darkwa, 1998). Cooking of $M$. cavendishii, at $120^{\circ} \mathrm{C}$ for $2 \mathrm{~h}$, and using $\mathrm{CaO}$ $(12 \%(\mathrm{w} / \mathrm{w}))$ as delignified agent gave $50 \%$ pulps yield (Soffner et al., 2000; Soffner and Silva, 2000).

\section{Experimental}

\subsection{Material and chemical analysis}

The pseudo-stems of $M$. acuminata Colla were harvested from a banana plantation in Funchal (Madeira Island, Portugal). The pseudo-stem of mature plants (after cutting the bananas bunch), randomly selected, were handily separated from foliage and several sheets of the trunk were disconnected. Afterwards they were air dried for 2 weeks. To carry out our experiments the initial raw material was divided in two types: (i) the whole material (type I) and (ii) the outer bark material (type II) which seemed to be richer in fibres. Both types of material were ground and the 60-80 mesh fraction was selected in order to determine its chemical composition, which is in agreement with standard Tappi T264 om-88.

The samples were first submitted to soxhlet extraction with ethanol/toluene $(1: 2(\mathrm{v} / \mathrm{v}))$ and water, for $8 \mathrm{~h}$. The determination of the ashes content, extractives, Klason lignin, holocellulose using peracetic method, cellulose following Kurschner-Hoffner approach and hemicelluloses I and II fractions, were performed following standards T211 cm-86, T204, T13 wd 674, Tappi useful method 249, for ashes, extractives and Klason lignin, respectively (Oliveira et al., 2002). The cellulose content was determined following Kurschner-Hoffner approach which consists of treating $5 \mathrm{~g}$ of extractives-free samples with $125 \mathrm{ml}$ of alcoholic nitric acid solutions under reflux during four cycles of $1 \mathrm{~h}$. After each cycle, the alcoholic nitric acid solution is removed and a fresh volume is added. The alcoholic nitric acid solution consisted in mixing one volume of $65 \%(\mathrm{w} / \mathrm{w})$ solution of nitric acid with four volumes of $96 \%$ purity ethanol (Browning, 1967). At the end of the four cycles, the cellulose was washed, dried and weighed. Holocelluloses were determined according to peracetic method which consisted of treating $10 \mathrm{~g}$ of free extractive banana crops with $500 \mathrm{ml}$ of peracetic acid solution and $25 \mathrm{~g}$ of sodium acetate during $70 \mathrm{~min}$ at $70-74^{\circ} \mathrm{C}$. The peracetic acid solution was prepared by mixing one volume of $30 \%$ hydrogen peroxide solution to an equivalent volume of pure acetic anhydride at $0-4{ }^{\circ} \mathrm{C}$. The solution was then kept at $6^{\circ} \mathrm{C}$ for $48 \mathrm{~h}$ before titration with $\mathrm{KMnO}_{4}$ in the presence of $\mathrm{H}_{2} \mathrm{SO}_{4}$. This solution was then diluted to $10 \%(\mathrm{w} / \mathrm{w})$ and used to isolate holocellulose. At the end of the reaction, the isolated polysaccharides were filtered, washed, dried and weighed.

The holocelluloses were fractionised by sequential extraction of with $5 \% \mathrm{KOH}$ aqueous solution (hemicellulose I) and $24 \% \mathrm{KOH}$ aqueous solution (hemicellulose II). The extracted fractions were then dried and weighed.

The polysaccharides of the extractive-free banana pseudo-stem materials were also analysed. In fact, 
the sugar composition of holocellulose, cellulose and hemicelluloses were determined by acid hydrolysis according to the TFA method (Fengel and Wegner, 1980) optimised by Gaiolas et al. (2003) followed by high performance liquid chromatography (HPLC) determination. The HPLC measurements were carried out using a Perkin-Elmer 250 Chromatograph equipped with a refractive index detector (HP 1074 A, Hewlett-Packard). The column used was a commercial polysphere CH-PB purchased from Merck. A flow rate of $0.4 \mathrm{ml} / \mathrm{min}$ bi-distilled water and a temperature of $80^{\circ} \mathrm{C}$ were used. Calibration curves of D-glucose, L-arabinose, D-xylose and D-mannose were obtained using high purity commercial sugars from Merck.

\subsection{Pulping}

In order to optimise the cooking conditions, chips of banana crops were prepared (approximately $10 \mathrm{~cm} \times$ $10 \mathrm{~cm}$ and $5-7 \mathrm{~mm}$ of thickness), and put on rotational thermostated mini-digesters having a volume of $100 \mathrm{ml}$ ( $20 \mathrm{~g}$ oven dried (o.d.) material) controlled by an ES100P apparatus. The effects of (i) raw material type; (ii) temperature: 90,120 and $160^{\circ} \mathrm{C}$; (iii) sodium hydroxide concentration (w/w with respect to o.d. material): $0,5,10,18,25$ and $50 \%$; (iv) liquor/crops ratio (1/kg): $3 / 1,5 / 1$ and $7 / 1$; (v) time at constant temperature: $15,30,45,60,120,180$ and $240 \mathrm{~min}$; (vi) anthraquinone concentrations (w/w with respect to o.d. material): $0,0.15,0.25$ and $0.35 \%$; and (vii) sodium sulphite concentrations (w/w with respect to o.d. material): 5 and $18 \%$, were studied. In all experiments, the heating time in order to reach the constant temperature was $1 \mathrm{~h}$.

After cooking, the cooked material was separated from black liquor, disintegrated, screened and washed abundantly with fresh water, using L\&W laboratory strainer. The disintegrator used, enabled the pulp screening which allowed, after drying, the determination of both total pulp yields and screening rejects by weighing each fraction. The residual lignin in the pulps was assessed by determining the Kappa no. The degree of polymerisation was calculated from viscosity data (TAPPI $206 \mathrm{~m}$-55). The sugar complex in different pulps was also determined by the method described below (Fengel and Wegner, 1980; Gaiolas et al., 2003).

\section{Results and discussion}

\subsection{Chemical composition}

The chemical composition of the two types of raw material is shown in Table 1. The first remark concerns the high amount of ashes (approximately 14\%) which is not common for annual plants (Atchison, 1993). The ashes were mainly constituted by $\mathrm{K}: 33.4 \%$; Ca: 7.5\%; Mg: 4.3\%; Si: $2.7 \%$ and P: $2.2 \%$. The high quantity of ashes is not dramatic in terms of pulping process, since the silicone-based salts are negligible. This ash content is still high for industry processing, in spite of the possibility that $50 \%$ of them can be extracted by washing before pulping, as determined in our laboratory.

The second remark is the considerably low amount of lignin, i.e. approximately $12 \%$, to compare with other annual plants, such as Hibiscus cannabinun (Pascoal Neto et al., 1996), Alfa tenassissima (Belgacem et al., 1986), or Cyanara cardunculus L. (Antunes et al., 1998, 2000), and lower than wood-based materials (Atchison, 1993). In spite of the high content of ashes, this raw material is worth pulping, mainly because of its relatively low lignin content.

The quantity of extractives in ethanol/toluene and water were 14.1 and $8.1 \%$, for the whole material

Table 1

Chemical composition of banana crops (\% w/w with respect to o.d. material)

\begin{tabular}{llllllll}
\hline & Ashes & \multicolumn{2}{l}{ Extractives } & & Lignin & Holocellulose $^{\mathrm{a}}$ & Cellulose $^{\mathrm{a}}$ \\
\cline { 3 - 6 } & & Diethyl ether & Ethanol/toluene & Water & & & \\
\hline Type I & 13.9 & 0.6 & 4.6 & 8.9 & 12.0 & 60.1 & 34.5 \\
Type II & 14.6 & 0.4 & 2.3 & 5.4 & 12.7 & 65.2 & 40.2 \\
\hline
\end{tabular}

${ }^{a}$ Corrected taking into account residual lignin. The relative errors of these data are in the range of $\pm 2-3 \%$. Type I: the whole material. Type II: the outer bark material, which seemed to be richer in fibres. 
(type I) and outer back material (type II), respectively, corresponding mainly to polar extractives (95-96\% of the total extractives). These values are relatively high when compared with wood and some other annual plants. Nevertheless, in some cases the amount of extractive components can be very high as for example for $C$. cardunculus L., 15-18\% (Antunes et al., 2000), or Arundo donax, 14-23\% (Pascoal Neto et al., 1997).

Table 1 also reports the results concerning the polysaccharide contents in both types of the residue studied here. Thus, the amount of holocellulose and cellulose for the type II material was higher than that of type I, which confirmed our visual observation concerning the outer bark material. Both values were reasonable, if one takes into account the high content of ashes and extractive components, and lead to promising perspectives concerning the use of these crops as a source of cellulose fibres, thus justifying the investigation dealing with the optimisation of the pulping process. The holocellulose content of the crops under investigation was higher than $60 \%$, with respect to o.d. material, meaning a hemicellulose/cellulose ratio about 1:2 which is common to other vegetal species. This ratio is very important if one considers the capital role which hemicelluloses play in papermaking.

The results of the monosaccharides composition analysis from pseudo-stem are shown in Table 2. Glucose is the predominant monomer in this raw material with $74.0 \%$ followed by xylose, $13.1 \%$; arabinose,

Table 2

Monosaccharides composition of Musa acuminata Colla pseudo-stem, holocellulose and hemicellulose (molar proportion, \%)

\begin{tabular}{lcccrc}
\hline Sample & \multicolumn{6}{l}{$\begin{array}{l}\text { Neutral sugar content } \\
\text { (molar proportions, \%) }\end{array}$} \\
\cline { 2 - 6 } & Glu & Xyl & Gal & Ara & Man \\
\hline Type I & & & & & \\
$\quad$ Pseudo-stem & 74.0 & 13.1 & 2.5 & 9.1 & 1.3 \\
Holocellulose & 80.2 & 10.8 & 1.7 & 5.7 & 1.6 \\
Hemicellulose I & 29.3 & 44.1 & 6.4 & 20.2 & nd \\
Hemicellulose II & 74.6 & 12.7 & 1.9 & 8.5 & 2.3 \\
Type II & & & & & \\
Holocellulose & 81.4 & 10.8 & 1.4 & 5.2 & 1.2 \\
Hemicellulose I & 23.0 & 51.3 & 6.1 & 19.6 & nd \\
Hemicellulose II & 71.5 & 19.2 & 2.0 & 5.4 & 1.9 \\
\hline
\end{tabular}

The relative errors of these data are in the range of $\pm 2-4 \%$.
9.1\%; galactose, $2.5 \%$ and mannose, $1.3 \%$. The values found for glucose were higher than those obtained for other annual plants like H. cannabinun (Pascoal Neto et al., 1996) or C. cardunculus L. (Antunes et al., 2000). The composition of holocellulose is close to that of initial raw material; nevertheless, the loss of some arabinoses, glucoses and xyloses shows the same selectivity of the isolation method.

The holocellulose fractionation by sequential extraction of with $5 \% \mathrm{KOH}$ aqueous solution (hemicellulose I) and 24\% $\mathrm{KOH}$ aqueous solution (hemicellulose II) was also analysed, and showed that the hemicellulose I is composed in major proportion by $\mathrm{xy}-$ lose (44\%), while hemicellulose II is composed mainly by glucose $(75 \%)$. The hemicellulose is composed by glucose, xylose, arabinose, galactose and mannose with molar proportion of 29:44:20:6:0, respectively for hemicellulose I and 75:13:8:2:2 for hemicellulose II.

Although the different contents of holocellulose and cellulose in the two types of material, the holocellulose and hemicellulose were constituted by the same monosaccharides albeit in different molar proportions (Table 2).

To the best of our knowledge, there are no detailed studies, on the quantification and characterisation of chemical constitution of the M. acuminata Colla; variety of banana plant, available in the literature. To fulfil this gap, we have recently started a research program aiming to deep the knowledge on chemical and structural constitution of the different morphological parts of banana plant.

\subsection{Optimisation of pulping process}

Before producing pulp from $M$. acuminata Colla pseudo-stem in a large scale and to avoid extensive consumption of raw material, delignification was carried out using rotational mini-digesters, which gave very suitable pulps to be investigated in terms of Kappa no., viscosity and sugar composition. The results obtained are shown in Figs. 1-3 and summarised in Tables 3-7. These data could be interpreted by following the next criteria.

\subsubsection{Influence of material type}

To study the behaviour of the two types of materials, we cooked banana pseudo-stem using $18 \%$ of sodium hydroxide, $0.15 \%$ of $\mathrm{AQ}$ and liquor/crops ratio: $5 / 1$, at 


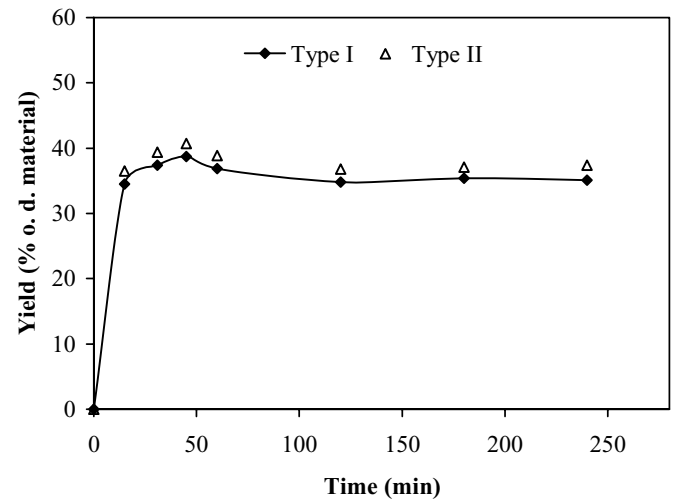

Fig. 1. Screened pulp yields as a function of cooking times for Musa acuminata Colla pseuto-stem crops. Cooking conditions: $18 \%$ of $\mathrm{NaOH}$ and $0.15 \%$ of anthraquinone (w/w with respect to o.d. material), a liquor/crops ratio: 5/1, $60 \mathrm{~min}$ of heating from room temperature to $120^{\circ} \mathrm{C}$ and maintaining the delay indicated in figure.

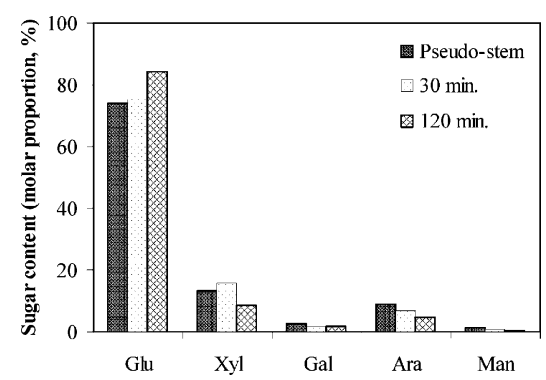

Fig. 2. Sugar composition as a function of cooking time.

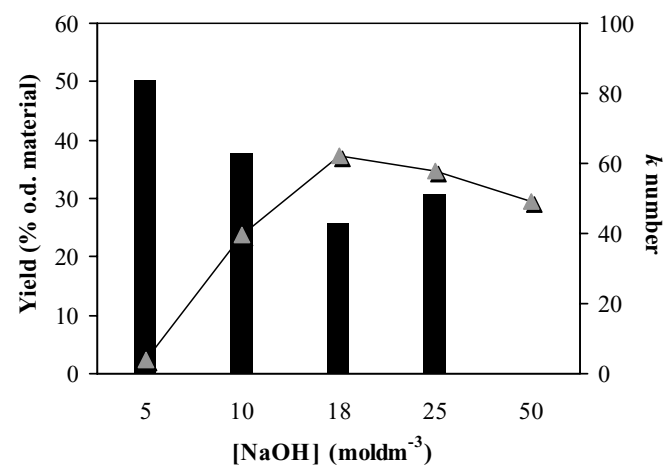

Fig. 3. Effect of the $\mathrm{NaOH}$ concentration on the screened pulp yield and Kappa no. (continuous line corresponds to the screened pulp yield whereas bars are relative to Kappa no.). Cooking conditions: a liquor/crops ratio: 5/1, $60 \mathrm{~min}$ of heating from room temperature to $120^{\circ} \mathrm{C}$ and maintaining the reaction for $30 \mathrm{~min}$.
Table 3

Kappa no., viscosity and degree of polymerisation as a function of delignification time

\begin{tabular}{llclll}
\hline & $\begin{array}{l}\text { Exp. } \\
\text { no. }\end{array}$ & $\begin{array}{l}\text { Time } \\
(\mathrm{min})\end{array}$ & $\begin{array}{l}\text { Kappa } \\
\text { no. }\end{array}$ & $\begin{array}{l}\text { Viscosity } \\
\left(\mathrm{g} / \mathrm{cm}^{3}\right)\end{array}$ & $\begin{array}{l}\text { Degree of } \\
\text { polymerisation }\end{array}$ \\
\hline $\mathrm{P}_{120} \mathrm{t}_{30}$ & 1 & 30 & 33.1 & 791 & 1254 \\
$\mathrm{P}_{120} \mathrm{t}_{60}$ & 2 & 60 & 32.8 & 614 & 948 \\
$\mathrm{P}_{120}$ & 3 & 120 & 31.5 & 534 & 812 \\
\hline
\end{tabular}

Cooking conditions: $18 \%$ of $\mathrm{NaOH}$ and $0.15 \%$ of anthraquinone (w/w with respect to o.d. material), a liquor/crops ratio: 5/1, $60 \mathrm{~min}$ of heating from room temperature to $120^{\circ} \mathrm{C}$. The relative errors of these data are in the range of $\pm 4-5 \%$.

different time at $120^{\circ} \mathrm{C}$ (Fig. 1). As expected, type II material with higher cellulose content, reveals higher yields in pulp fibres. Nevertheless, the gain of the yield was modest, which is not significant enough to justify the addition of the crops separation. Thus, we decided to pulp the whole material and to study the other cooking variables. The Kappa no. for $30 \mathrm{~min}$ was 33.1 and 30.2 , for types I and II, respectively.

\subsubsection{Influence of time process}

The delignification kinetics of $M$. acuminata Colla pseudo-stem was also studied, and is shown in Fig. 1. As it can be seen (i) the maximum yield was reached at $30-45 \mathrm{~min}$, which is a very short cooking time; (ii) for times higher than 45 min the cooking time did not affect significantly the pulps yield. From Table 3 we can see that increasing the reaction time, decreased modestly the Kappa no. of the pulps, but at the same time induced polysaccharide degradation, as seen by

Table 4

Monosaccharide composition of pulps, obtained with different cooking conditions, from Musa acuminata Colla pseudo-steam (molar proportion, \%)

\begin{tabular}{rlrrrrr}
\hline Exp. no. & & \multicolumn{5}{c}{$\begin{array}{l}\text { Neutral sugar content } \\
\text { (molar proportions, \%) }\end{array}$} \\
\cline { 3 - 7 } & & Glu & Xyl & Gal & Ara & Man \\
\hline 13 & $\mathrm{P}_{90}$ & 72.9 & 9.6 & 4.1 & 11.6 & 1.8 \\
3 & $\mathrm{P}_{120}$ & 84.5 & 9.0 & 1.2 & 4.3 & 1.0 \\
15 & $\mathrm{P}_{160}$ & 80.4 & 11.1 & 1.7 & 5.5 & 1.3 \\
11 & $\mathrm{P}_{10}$ & 75.2 & 9.9 & 3.5 & 9.7 & 1.7 \\
12 & $\mathrm{P}_{25}$ & 83.9 & 8.4 & 1.6 & 5.5 & 0.6 \\
7 & $\mathrm{P}_{120} \mathrm{AQ}_{0.25} \mathrm{t}_{30}$ & 75.4 & 15.6 & 1.6 & 6.7 & 0.7 \\
18 & $\mathrm{P}_{120} \mathrm{AQ}_{0.25} \mathrm{t}_{120}$ & 84.4 & 8.7 & 1.7 & 4.6 & 0.6 \\
10 & $\mathrm{P}_{120} \mathrm{~S}_{18}$ & 81.2 & 9.7 & 1.6 & 6.4 & 1.1 \\
\hline
\end{tabular}

The relative errors of these data are in the range of $\pm 3-4 \%$. 
Table 5

Pulping conditions of Musa acuminata Colla and the properties of the obtained pulps (w/w with respect to o.d. material)

\begin{tabular}{|c|c|c|c|c|c|c|c|c|}
\hline & Exp. no. & $\mathrm{NaOH}(\%)$ & AQ (\%) & $\mathrm{Na}_{2} \mathrm{~S}(\%)$ & Yield (\%) & Kappa no. & Viscosity $\left(\mathrm{g} / \mathrm{cm}^{3}\right)$ & $\begin{array}{l}\text { Degree of } \\
\text { polymerisation }\end{array}$ \\
\hline $\mathrm{P}_{5}$ & 4 & 5 & 0 & 0 & 2.3 & 83.7 & - & - \\
\hline $\mathrm{P}_{10}$ & 5 & 10 & 0 & 0 & 23.7 & 63.1 & 451 & 674 \\
\hline $\mathrm{P}_{120}$ & 3 & 18 & 0 & 0 & 37.4 & 43.0 & 564 & 863 \\
\hline $\mathrm{P}_{120} \mathrm{AQ}_{0.15}$ & 6 & 18 & 0.15 & 0 & 40.2 & 33.1 & 791 & 1254 \\
\hline $\mathrm{P}_{120} \mathrm{AQ}_{0.25}$ & 7 & 18 & 0.25 & 0 & 38.2 & 32.4 & 870 & 1393 \\
\hline $\mathrm{P}_{120} \mathrm{AQ}_{0.35}$ & 8 & 18 & 0.35 & 0 & 37.0 & 30.6 & - & - \\
\hline $\mathrm{P}_{120} \mathrm{~S}_{5}$ & 9 & 18 & 0 & 5 & 26.2 & 56.2 & 650 & 1009 \\
\hline $\mathrm{P}_{120} \mathrm{~S}_{18}$ & 10 & 18 & 0 & 18 & 28.2 & 50.3 & 613 & 989 \\
\hline $\mathrm{P}_{25}$ & 11 & 25 & 0 & 0 & 34.6 & 51.5 & 550 & 839 \\
\hline $\mathrm{P}_{50}$ & 12 & 50 & 0 & 0 & 29.5 & - & - & - \\
\hline
\end{tabular}

Cooking conditions: liquor/crops ratio: $5 / 1,60 \mathrm{~min}$ of heating from room temperature to $120^{\circ} \mathrm{C}$ and maintaining the reaction for 30 min. The relative errors of these data are in the range of $\pm 4-5 \%$.

Table 6

Yield and pulp characteristics obtained with different temperatures of soda process

\begin{tabular}{lccccccc}
\hline & Exp. no. & Temperature $\left({ }^{\circ} \mathrm{C}\right)$ & Time $(\mathrm{min})$ & Yield $(\%)$ & Kappa no. & Viscosity $\left(\mathrm{g} / \mathrm{cm}^{3}\right)$ & $\begin{array}{l}\text { Degree of } \\
\text { polymerisation }\end{array}$ \\
\hline $\mathrm{P}_{90}$ & 13 & 90 & 30 & 13.4 & 58.0 & 422 & 626 \\
$\mathrm{P}_{90} \mathrm{~T}_{180}$ & 14 & 90 & 180 & 28.0 & - & - & - \\
$\mathrm{P}_{120}$ & 3 & 120 & 30 & 35.8 & 43.0 & 564 & 863 \\
$\mathrm{P}_{160}$ & 15 & 160 & 30 & 28.6 & 42.5 & 499 & 754 \\
\hline
\end{tabular}

Cooking conditions: $18 \%$ of $\mathrm{NaOH}$ (w/w with respect to o.d. material), a liquor/crops ratio: 5/1, 60 min of heating from room temperature to final temperature and maintaining the delay indicated in the table. The relative errors of these data are in the range of $\pm 4-5 \%$.

the decrease of the viscosity and consequently the decrease of polymerisation degree. This indicates that cooking with shorter time might offers pulps with better quality.

Besides the determination of the individual sugar content of M. acuminata Colla pseudo-stem, holocellulose and cellulose, reported in Table 2, and already discussed in Section 3.1, we also studied the sugar composition of pulps, obtained with different cooking conditions, as summarised in Table 4. From these data a first remark could be drawn: in different pulps the major monosaccharides present are glucose, xy- lose and arabinose. Galactose and mannose are also present although in minor extent (less than $6 \%$ of the total of monosaccharide).

The effect of pulping process time on the sugar composition could be observed by exp. nos. 7 and 18 (Table 4). These results show that the longer time cooked pulp has lower proportions of xylose, galactose and arabinose (Fig. 2), indicating that for longer cooking times, a higher degradation of hemicelluloses took place. This factor could be a justification for the decrease of the viscosity parameter with time, as discussed above.

Table 7

Yield and pulp characteristics obtained with different ratio of liquor/crops of soda process

\begin{tabular}{lclllll}
\hline & Exp. no. & Liquor/raw material $(1 / \mathrm{kg})$ & Yield $(\%)$ & Kappa no. & Viscosity $\left(\mathrm{g} / \mathrm{cm}^{3}\right)$ & $\begin{array}{l}\text { Degree of } \\
\text { polymerisation }\end{array}$ \\
\hline $\mathrm{P}_{120}$ LB3/1 & 16 & $3 / 1$ & 21.1 & 53.9 & 546 & 833 \\
$\mathrm{P}_{120}$ & 3 & $5 / 1$ & 35.8 & 43.0 & 564 & 863 \\
$\mathrm{P}_{120}$ LB7/1 & 17 & $7 / 1$ & 23.4 & 50.5 & 497 & 750
\end{tabular}

Cooking conditions: $18 \%$ of $\mathrm{NaOH}$ (w/w with respect to o.d. material), 60 min of heating from room temperature to $120^{\circ} \mathrm{C}$ and maintaining the reaction for $30 \mathrm{~min}$. The relative errors of these data are in the range of $\pm 4-5 \%$. 


\subsubsection{Influence of the sodium hydroxide concentration}

The sodium hydroxide varied from 0 to $50 \%$ (w/w of o.d. material). The conditions used and some characterisations of the obtained pulp are summarised in Table 5. In the absence of sodium hydroxide, pulping did not occur. The increase in the sodium hydroxide concentration from 5 to $18 \%$ produced an increase in the screened pulp yield, from 2.3 to $37.4 \%$, and a decrease in Kappa no. of pulps from 84 to 43, as shown in Fig. 3. This is probably due to the very weak alkali level in the first reaction system. For higher sodium hydroxide concentration, up to $25 \%$, a decrease of the pulp yield was observed. This is due to the cellulosic fibres degradation, as stated by decreasing viscosity, and did not yield additional delignification because Kappa no. increased, possibly due to self-condensation reactions of lignin macromolecules.

Despite the fact that the yields are lower than those obtained from wood species and from some other annual plants (Atchison, 1993), the overall yield of pulp obtained with our raw material can be considered as acceptable, if one takes into account the fact that original material contains high amounts of ashes.

With respect to sugar composition we can see, by the data in Table 4, that pulps obtained at minor concentration of sodium hydroxide $(10 \%)$ presented a very similar monosaccharide composition to raw material. For 18 and $25 \%$ of sodium hydroxide we can observe an increase in glucose proportion indicating a preferential extraction of cellulose in stronger alkaline conditions.

\subsubsection{Influence of anthraquinone and sulphite addition in pulp process}

The effect of the addition of AQ on the pulp yield of our material has also been studied, as shown in Table 5 (exp. nos. 6, 7 and 8). The addition of catalytic amounts of about $0.15 \%$ (w/w o.d. material), $\mathrm{P}_{120} \mathrm{AQ}_{0.15}$, revealed a slight increase of the pulp yield and a significant decrease of the Kappa no. The Kappa no. of the unbleached pulps reached a value of about 30 , which is very interesting for our plant in particular, and for annual plants in general. The Klason lignin content in pulps was also determined and the results showed the same tendency as Kappa no.

With the addition of sulphite, 5 and $18 \%$ (w/w o.d. material) the yields were lower than those obtained in the absence of this additive and the Kappa no. became significantly higher. However, the pulps thus obtained possessed a higher viscosity and consequently a higher degree of polymerisation, as shown in Table 5 (exp. nos. 9 and 10). Due to the quite modest gain of yield with the addition of catalysts, $\mathrm{AQ}$ and $\mathrm{Na}_{2} \mathrm{~S}$, we decided to carry out the delignification processes only with sodium hydroxide.

The sugar composition (Table 4, exp. nos. 7 and 10) showed that the catalytic effect of anthraquinone and sulphite provoked a preferential extraction of cellulose.

\subsubsection{Influence of temperature and liquor/crops ratio}

Tables 6 and 7 show the values obtained for yield, Kappa no., viscosity and degree of polymerisation, as a function of the variation in cooking temperature and liquor/banana crops ratio, respectively. The highest yield was reached at $120^{\circ} \mathrm{C}$ and liquor/banana crops ratio of 5/1. Pulping at higher temperature significantly decreased the pulp yield and the viscosity, without significantly decreasing the Kappa no. liquor/banana crops ratio of $3 / 1$ or $7 / 1$ decreased considerably the pulp yield and increased the Kappa no.

The amount of each monosaccharide (Table 4) in the pulp obtained at lower temperature $\left(90^{\circ} \mathrm{C}\right)$ is similar to that observed for raw material, but with higher temperatures $\left(120\right.$ and $\left.160^{\circ} \mathrm{C}\right)$ a decrease of glucose proportion was observed indicating a preferential degradation of cellulose.

\section{Conclusions}

The main objective of this study was to establish the suitability of $M$. acuminata Colla as a potential source of lignocellulosic fibres for paper and composites materials. By the present study in chemical composition and pulping optimisation process we conclude that: (i) regardless the high amount of ashes a good yield of pulping is obtained with an acceptable Kappa no.; (ii) the banana pseudo-stem separation in two parts did not present any significant increase in the pulp yield, which justify an additional separation operation in the crops, although the holocellulose content was found to be higher in the outer bark part; (iii) the optimal conditions of cooking are soft comparing to those used for vegetal species; (iv) the 
monosaccharides composition study, of the different pulps obtained, show that in soft conditions the extraction of cellulose and hemicelluloses are similar, but in harder conditions the extraction of cellulose is preferential. The suitability of these fibres in the papermaking, boards and composite materials areas are under investigation and will be reported shortly.

\section{Acknowledgements}

The authors wish to thank to FCT and JNICT/ French-Portuguese Scientific Co-operation Programme for financial support.

\section{References}

Antunes, A., Amaral, E., Belgacem, M.N., Silvy, J., 1998. Da Cynara cadunculus até ao papel. In: Proceedings of the 16th Tecnicelpa Meeting, 29-31 October 1998. Covilhã, Portugal, pp. 136-145.

Antunes, A., Amaral, E., Belgacem, M.N., 2000. Cynara cardunculus L.: chemical composition and soda-anthraquinone cooking. Ind. Crops Prod. 12, 85-91.

Atchison, J.E., 1993. Data on non-wood plant fibers. In: Hamilton, F., Leopold, B. (Eds.), Pulp and Paper Manufacture, vol. III. TAPPI Press, Atlanta, pp. 157-163.

Belgacem, M.N., Zid, M., Nicolski, S.N., Obolenskaya, A.V., 1986. Study of the chemical composition of alpha from Tunisia. Chim. Technol. Drev., Mej. Sbor. Trud., vol. 1, 111-114.

Browning, B.L., 1967. Methods of Wood Chemistry, vol. II. Interscience/Wiley, New York.

Darkwa, N.A., 1998. Plantain (Musa paradisiacal L) pseudostem: a fibre source for tropical countries. In: Proceedings of the 1998 Pulping Conference, Montreal, Que., Canada, 25-29 October 1998. TAPPI Press, Atlanta, GA, USA, pp. 645-649 (Book 2).
Faria, H., Oliveira, L., Cordeiro, N., Belgacem, M.N., 2002. Dwarf Cavendish as a source of natural fibres. Chemical modification and evaluation of process efficiency. International Congress in Production, Processing and Use of Natural Fibres. Potsdam, Berlin.

Fengel, D., Wegner, G., 1980. Hydrolysis of polysaccharides with trifluoroacetic acid and its application to rapid wood and pulp analysis. In: Brown R.D. (Eds.), Hydrolysis of Cellulose: Mechanisms of Enzymatic and Acid Catalysis. Jurasek, pp. 145-158.

Gaiolas, C., Duarte, A.P., Belgacem, M.N., Simões, R., 2003. Determination of sugars content in Pinus pinaster and its corresponding polysaccharide complex and kraft pulps. Cellulose Chem. Technol. 37, 43-51.

Neto, C., Seca, A., Fradinho, D., Coimbra, M.A., Domingos, F., Evtuguin, D., Silvestre, A., Cavaleiro, J.A.S., 1996. Chemical composition and structural features of the macromolecular components of Hibiscus cannabinus grown in Portugal. Ind. Crops Prod. 5, 189-196.

Neto, C., Seca, A., Nunes, A.M., Coimbra, M.A., Domingos, F., Evtuguin, D., Silvestre, A., Cavaleiro, J.A.S., 1997. Variations on chemical composition and structural features of macromolecular components in differents morphological regions and maturity stages of Arundo donax. Ind. Crops Prod. $6,51-58$.

Oliveira, L., Cordeiro, N., Torres, I.C., Silvestre, A., 2002. Dwarf Cavendish: chemical composition in different morphological regions-preliminary results. In: Proceedings of the 12th European Conference and Technology Exhibition on Biomass for Energy, Industry and Climate Protection, Amsterdam, The Netherlands.

Soffner, M.L.A.P., Silva, F.G. Jr., 2000. Evaluation of the primary depitthing of banana stem as pre-processing for pulping. In: Proceedings of the Fourth International Nonwood Fibre Pulping and Papermaking Conference, vol. 1. Jinan, China, 18-21 September 2000, pp. 185-193.

Soffner, M.L.A.P., Silva, F.G. Jr., Brito, J.O., Pereira, L.L., 2000. Evaluation of the primary depitthing of banana stem as pre-processing for pulping. In: Proceedings of the Fourth International Nonwood Fibre Pulping and Papermaking Conference, vol. 2. Jinan, China, 18-21 September 2000, pp. 535-541. 